\title{
A Doutrina Social no magistério de Franciseo
}

\section{Social Doctrine in the magisterium of Francis}

\author{
Elias Wolff* \\ PUC-PR
Tiago Trevisan**
PUC-PR

Recebido em: 01/03/2021. Aceito em: 26/03/2021.

Resumo: A Doutrina Social da Igreja apresenta orientações de como viver o Evangelho nas relações sociais e com todas as criaturas, propondo ações concretas para a construção da paz e da justiça nas relações entre pessoas, povos e nações. Francisco com o seu magistério social contribui de modo significativo para superar as dificuldades que o mundo enfrenta para afirmar a dignidade da vida humana e de toda a criação. O presente artigo aborda alguns temas sociais no magistério de Francisco, que compõem a doutrina social da Igreja num modo bem próprio do seu pontificado. A metodologia adotada neste artigo consiste em uma pesquisa qualitativa. As fontes primordiais são os documentos emanados pelo Papa Francisco e comentários a respeito em livros e artigos científicos. A perspectiva da análise é a teologia conciliar e latino-americana. A conclusão é que Francisco, inserido na história atual da humanidade e atento às suas múltiplas questões, desenvolve processos que, fundamentados na fé cristã, incidem na vida das pessoas e dos povos, convocando ao encontro e diálogo que possibilita cooperação para transformar o que não condiz com a vida na dignidade, na justiça e na paz, condições para a fraternidade universal.

* Doutor em Teologia (Pontifícia Universidade Gregoriana, Roma, 2000). Mestre em Filosofia (Pontifícia Universidade Santa Cruz, Roma, 1999). Mestre em Teologia (Pontifícia Universidade Gregoriana, Roma, 1998). Graduado em Teologia (Faculdade Jesuíta de Filosofia e Teologia, FAJE, Belo Horizonte, 1993).

E-mail: elias.wolff@pucpr.br

** Mestrando em Teologia (Pontifícia Universidade Católica do Paraná, Curitiba). Graduado em Teologia (Pontifícia Universidade Católica do Paraná, Curitiba, 2020). Graduado em Pedagogia (Faculdade de Campina Grande do Sul - FACSUL, Campina Grande, 2016).

E-mail: trevisaan@gmail.com 
Palavras-chave: Doutrina social. Cultura do encontro e do diálogo. Fraternidade universal.

Abstract: The Church's Social Doctrine presents guidelines on how to live the Gospel in social relations and with all creatures, proposing concrete actions for the construction of peace and justice in relations between individuals, peoples and nations. Francis, with his social teaching, contributes significantly to overcome the difficulties that the world faces in affirming the dignity of human life and of all creation. This article deals with some social themes in Francis'magisterium, which make up the Church's social doctrine in a very specific way of his pontificate. The methodology adopted in this article consists of a qualitative research. The primary sources are the documents issued by Pope Francis and comments on them in books and scientific articles. The perspective of the analysis is conciliar and Latin American theology. The conclusion is that Francis, inserted in the current history of humanity and attentive to its multiple questions, develops processes that, based on the Christian faith, affect the lives of individual and peoples, calling for meetings and dialogue that enables cooperation to transform what it matches life in dignity, justice and peace, conditions for universal brotherhood.

Keywords: Social doctrine. Culture of encounter and dialogue. Universal brotherhood.

\section{Introdução}

A Doutrina Social apresenta-se hoje como um campo que aos poucos vai sendo descoberto, tanto pelos cristãos quanto pelo mundo. Resultado do magistério pontifício católico desde Leão XIII, com a encíclica Rerum Novarum (15/05/1891), assumido pelas Conferências Episcopais em diferentes regiões e espaços eclesiásticos, esse ensino fortalece as iniciativas que promovem vida humana e seus direitos, estabelecendo parcerias com a sociedade e pessoas "de boa vontade", crentes ou não. O papa Francisco colabora nesse processo, abrindo-se às questões ambientais com a encíclica Laudato $\mathrm{Si}^{\prime}$ (24/05/2015), estreitando promovendo o diálogo e a cooperação conjunta a favor da "Casa Comum".

Ao longo da história humana, muitos e enormes são os desafios que surgem constantemente para a construção da fraternidade universal, que o papa Francisco identifica na encíclica Fratelli Tutti (03/10/2020) como "sombras de um mundo fechado" (FT 9-56) como o nacionalismo fechado e agressivo, as expressões de racismo, o trabalho escravo, as relações marcadas pelo ódio e destruição, as ilusões da comunicação, as questões ambientais, entre outras. O Papa Francisco, atento a essa realidade, contribui por meio de seu magistério e essas abordagens justificam a relevância deste artigo que almeja somar-se aos esforços, a 
fim de elucidar que há um caminho de esperança que, marcado pelo bem comum e pela fraternidade, pode inaugurar um tempo novo.

O presente artigo objetiva explicitar alguns dos temas que constituem a Doutrina Social da Igreja enfatizados no magistério do Papa Francisco. Para tanto, percorre-se o mesmo, tendo por base a exortação apostólica Evangelii Gaudium e as encíclicas Laudato $\mathrm{Si}^{1} \mathrm{e}$ Fratelli Tutti ${ }^{2}$. Retoma-se brevemente a doutrina social da Igreja e nela contextualiza-se o pontificado de Francisco, dando particular atenção à sua proposta de uma "cultura do diálogo", que apresenta interpelações à igreja e ao mundo. Com essa base, o artigo foca na análise de algumas temáticas abordadas no magistério de Francisco, como: o princípio do bem comum, a paz social e justiça intergeracional; a opção preferencial pelos pobres; a ecologia integral, a fraternidade e a amizade social. Naturalmente, não se propõe esgotar a abordagem desses temas, mas espera-se favorecer a sua compreensão e recepção no modus essendi et operandi da igreja.

Para tanto, na primeira seção é brevemente abordada a doutrina social e as marcas do magistério de Francisco, sobretudo as suas interpelações. Na segunda seção, serão elucidados alguns dos temas sociais tratados pelo papa, a saber: o princípio do bem comum, a paz social e justiça intergeracional, a opção preferencial pelos pobres, ecologia integral, a fraternidade e amizade social.

\section{A Doutrina Social da Igreja: um tesouro da humanidade}

A Doutrina Social da Igreja ${ }^{3}$, no sentido que a tradição católica a entende hoje, inicia em 1891, com a encíclica Rerum Novarum, do papa Leão XIII ${ }^{4}$. Desde então, todos os papas publicaram documentos, refletindo sobre questões sociais e buscando respostas aos desafios

\footnotetext{
FRANCISCO, Papa. Carta Encíclica Laudato Si. São Paulo: Paulus: Loyola, 2015. Daqui em diante: LS.

2 FRANCISCO, Papa. Carta Encíclica Fratelli Tutti. São Paulo: Paulinas, 2020. Daqui em diante: FT.

3 Daqui em diante $=$ DSI.

4 LEÃO XIII, Papa. Carta Encíclica Rerum Novarum: Sobre a condição dos operários. Disponível em: http://www.vatican.va/content/leo-xiii/pt/encyclicals/documents/hf_I-xiii_enc_15051891_rerum-novarum.html. Acesso em: 15 fev. 2021.
} 
socioculturais de cada época ${ }^{5}$. Há mais de 100 anos, os Papas e as Conferências Episcopais têm ecoado palavras firmes e claras a respeito da pessoa humana e dos seus direitos. ${ }^{6}$ Diante disso, "a Igreja, perita em humanidade, em uma espera confiante e ao mesmo tempo operosa, continua a olhar para os 'novos céus' e para a 'terra nova' $(2 \mathrm{Pd} 3,13)$ e a indicá-los a cada homem, para ajudá-lo a viver a sua vida na dimensão do sentido autêntico".?

Assumindo a missão de anunciar o Evangelho do Reino ao mundo, a Igreja, por meio da DSI, segue atualizando a sua mensagem de libertação e de redenção. Assim, evangelizar o social é soprar no coração do ser humano a carga de sentido e de libertação do Evangelho, a fim de se construir uma sociedade, mais humana, no horizonte do Reino de Deus. A DSI compõe o ministério da igreja, o seu discipulado e a sua fidelidade à missão, de modo que tido o que diz respeito à comunidade humana não the é alheio. ${ }^{8}$

Assim, a DSI possui uma natureza teológica, mais especificamente teológico moral, visando orientar comportamento social dos fiéis católicos, mas com propostas que implicam na vida de todo ser humano. A DSI "situa-se no cruzamento da vida e da consciência cristã com as situações do mundo e exprime-se nos esforços que indivíduos, famílias, agentes culturais e sociais, políticos e homens de Estado realizam para lhe dar forma e aplicação na história". ${ }^{9}$

Mesmo que os documentos católicos destinem-se primeiramente a um segmento específico do cristianismo, seu ensino tem características universais, convidando todas as pessoas, indistintamente, a percorrer caminhos de justiça e de paz. Assim, a DSI apresenta princípios que podem guiar ações em todo o mundo, a fim de construir a justiça e a paz ${ }^{10}$. Para

5 MARTINS, Alexandre Andrade. Doutrina Social da Igreja e Teologia da Libertação: diferentes abordagens. In: ZACHARIAS, Ronaldo; MANZINI, Rosane (org.). Magistério e doutrina social da Igreja. São Paulo: Paulinas, 2016. p. 53.

6 STRINGHINI, Pedro Luiz. Apresentação. In: ZACHARIAS, Ronaldo; MANZINI, Rosane (org.). Magistério e doutrina social da Igreja. São Paulo: Paulinas, 2016. p. 5.

7 PONTIFÍCIO CONSELHO JUSTIÇA E PAZ. Compêndio da Doutrina Social da Igreja. Disponível em: http://www.vatican.va/roman_curia/pontifical_councils/justpeace/documents/rc_pc_justpeace_doc_20060526_compendio-dott-soc_po.html. Acesso em: 8 jan. 2021. Apresentação. Daqui em diante = PCJP.

8 PCJP, 2004, n. 67-68.

9 PCJP, 2004, n. 67.

10 MARTINS, 2016, p. 55-56. 
isso, a Igreja entende que tem "a competência que lhe vem do Evangelho: da mensagem de libertação do homem anunciada e testemunhada pelo Filho de Deus humanado". ${ }^{11}$

Ademais, atenta à história e interpelada pelos eventos que nela acontecem, a DSI apresenta sua capacidade de renovar-se constantemente. Orientada pela luz do Evangelho se caracteriza pela continuidade e renovação e se "apresenta assim como um 'canteiro' sempre aberto, em que a verdade perene penetra e permeia a novidade contingente, traçando caminhos inéditos de justiça e de paz". ${ }^{12}$

\section{O pontificado de Francisco: luz e esperança}

O pontificado do Papa Francisco é marcado pelo esforço incansável para promover comportamentos e atitudes que se caracterizem pela proximidade entre as pessoas, a escuta mútua, o ato de olhar nos olhos e olhar na mesma direção, o que possibilita conhecimento mútuo, cooperação e comunhão. ${ }^{13}$ Esse esforço coloca Francisco num horizonte fraternal, com relações frutuosas dentro da Igreja - não obstante as resistências que enfrenta - bem como no mundo. Os Critérios para essa relação é o "Evangelho da alegria" ${ }^{14}$, anunciado, testemunhado e vivido concretamente na busca do bem comum.

\subsection{Francisco, o Papa do diálogo}

Ao ser eleito Francisco deparou-se com a necessidade de assumir uma reforma da Igreja e de chamar o povo cristão a voltar-se ao Evangelho acolhido, vivido e proclamado. ${ }^{15}$ Deste modo, Francisco contra no diálogo um caminho de transformação. Não como mera pronúncia de palavras, mas como convicção: somos diálogo. O papa vive e propõe um "diálogo aberto"16, amplo e profundo, do qual ninguém está excluído. Estabelece relações com as pessoas, a sociedade, as diversas

\footnotetext{
11 PCJP, 2004, n. 68.

12 PCJP, 2004, n. 76-86.

13 Fratell Tutti, 198. Daqui em diante $=$ FT.

14 FRANCISCO, Papa. Exortação Apostólica Evangelli Gaudium. São Paulo: Paulus: Loyola, 2014. n. 1, 21, 23. Daqui em diante = EG.

15 GABRIELE CIPRIANI. Da fraternidade à comunhão: o ecumenismo do papa Francisco. Caminhos de Diálogo. Curitiba, ano 6, n. 8, p. 8-18, jan./jun. 2018. 
igrejas, religiões e culturas. O papa argentino busca, assim, construir pontes com o objetivo de aproximar diferentes instâncias, tanto nas relações internas da igreja (ad intra), quanto nas relações externas a ela (ad extra). ${ }^{17}$

Essa postura coloca o Papa Francisco na direção do Concílio Vaticano II, que orienta a comunidade dos que creem para "a relação da Igreja com o mundo, colhendo os 'sinais dos tempos', as solicitudes para missão, exercendo a solidariedade e o companheirismo"18. Enfatizando o ensino conciliar, Francisco vai ao encontro das diferenças e colhe delas contribuições para a compreensão e pregação do Evangelho. Desse modo, o fundamento do diálogo está na fé em Cristo, contemplando sua proximidade, atenção e cuidado para com as pessoas tal como ensina, por exemplo, a parábola do Bom Samaritano ${ }^{19}$.

Disso depreende-se a compreensão de discipulado e de missão da igreja. Não é uma igreja julgadora de quem é diferente, mas uma igreja que se coloca em postura de escuta e busca de compreensão da verdade que o outro expõe, ou seja, uma "Igreja em saída" ${ }^{20}$, que se faz próxima e companheira. Nas situações difíceis em que o mundo vive, a Igreja se faz companheira e parceira na busca de superação dos problemas, como as contradições e ambiguidades da globalização na lógica do mercado, as fragilidades sociais que se intensificam pela atual pandemia do novo coronavírus e da Covid 19, entre outras. O discipulado e seguimento de Cristo coloca a igreja numa atitude de serva e humildade na busca conjunta do bem comum, da verdade, do que possibilita a realização da humanidade em conformidade com o Evangelho da "vida em abundância" (Jo 10,10). Atento ao que o Concílio Vaticano II propôs, Francisco dialoga, concretamente, sobre os elementos socioculturais e religiosos que hoje interpelam a fé cristã e a missão da igreja, como orientam, por exemplo, os documentos conciliares Gaudium et spes ${ }^{21}$, Unitatis redintegratio, Nostra aetate, Dignitatis humanae, entre outros. ${ }^{22}$

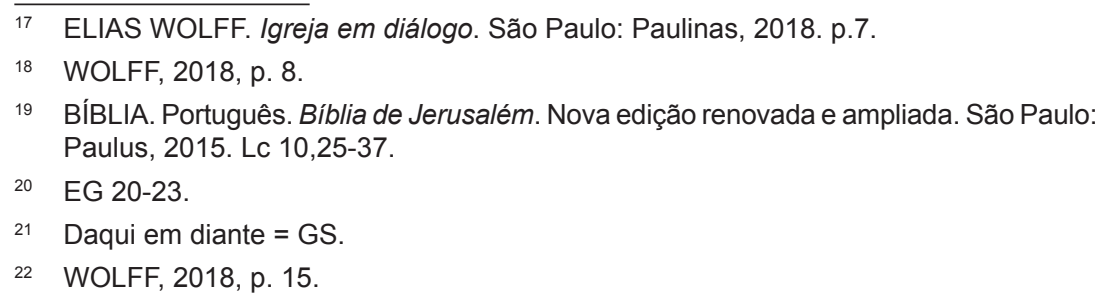




\subsection{O magistério social de Francisco e suas interpelações}

$\mathrm{Na}$ esteira desses documentos conciliares, e em comunhão com seus antecessores, Francisco dá continuidade ao ensino social da igreja através das encíclicas Laudato Sí e Fratelli Tutti, embora não sejam os únicos textos que tratam de questões socioambientais, como se verifica, por exemplo, na Evangelii Gaudium. Tais documentos possuem duas principais particularidades. A primeira é que integram vozes da Igreja Católica, oriundas de várias partes do mundo, de modo que ele cita não somente os papas que lhe antecederam, mas apresenta como fonte também documentos das conferências episcopais de várias partes do mundo. Uma segunda particularidade é que Francisco valoriza, de modo positivo e prático, o diálogo com as ciências, com as outras tradições religiosas e com o mundo secular. ${ }^{23}$

Diante da primeira particularidade, Francisco dá voz de modo especial às Conferências Episcopais do Sul, entre elas a África do Sul, Filipinas, Bolívia, Brasil, Nova Zelândia, Austrália e Federação das Conferências Episcopais da Ásia ${ }^{24}$. Na exortação apostólica Evangelii Gaudium, o Francisco apresenta as linhas-mestras do seu pontificado, tendo como foco os sujeitos, as instâncias e os processos de uma nova agenda evangelizadora da Igreja, tendo por prioridade os "mais indigentes". ${ }^{25}$

A Laudato Si insere-se no magistério social da igreja, como Francisco explicita logo no início desse documento, convidando a todos para o cuidado da Casa Comum, o que exige "reconhecer a grandeza, a urgência e a beleza do desafio que temos pela frente" 26 . Nessa encíclica, Francisco percorre o seguinte caminho: apresenta os aspectos da crise ecológica, e partindo dela, então, apresenta uma base concreta para o percurso ético e espiritual ${ }^{27}$. Dando sequência, o papa retoma os argumentos da tradição judaico-cristã. ${ }^{28}$

Posteriormente, ele apresenta as raízes da situação da atual crise ecológica, identificando as suas causas ${ }^{29}$. A partir disso, o pontífice,

\footnotetext{
23 MARTINS, 2016, p. 56-57.

24 MARCIAL MAÇANEIRO. Vozes do sul na encíclica Laudato si': Fontes e temas. Pistis \& Praxis - Teologia e Pastoral. Curitiba, v. 8, n. 3, p. 715-760, set./dez. 2016. p. 757 
propõe uma "ecologia integral" ${ }^{30}$. Na sequência, o papa aponta grandes linhas de ação ${ }^{31}$. Por fim, afirmando que toda a mudança passa por um caminho educativo, apresenta as linhas de maturação humana, inspiradas na experiência espiritual cristã. ${ }^{32}$

A encíclica Fratelli Tutti, insere-se também no magistério social da igreja, conforme afirma Francisco, no parágrafo 6. Nela Francisco dedica-se a tratar do amor fraterno, na amizade entre os povos, em sua dimensão local e universal. Com isso, o pontífice visa buscar caminhos para superar as várias formas de eliminar atitudes de intolerância e de indiferença entre pessoas e povos, com suas culturas e credos, a fim de que todas as pessoas possam trabalhar na construção de "um novo sonho de fraternidade e amizade social que não se limite a palavras" ${ }^{33}$.

A Fratelli Tutti percorre o seguinte itinerário: apresenta tendências do mundo atual, que dificultam o desenvolvimento da fraternidade universal, identificando "sombras de um mundo fechado" 34; aponta luz para dissipar essas sombras, tendo como raio da parábola do "bom samaritano" (Lc 10, 25-37) ${ }^{35}$. Na sequência, recorda-se que o ser humano realiza-se e desenvolve-se por meio do encontro ${ }^{36}$. Desse modo, afirmar que os seres humanos são todos irmãos e irmãs não é uma abstração, mas um modo concreto de viver que provoca todas as pessoas a se moverem na direção de um encontro mútuo ${ }^{37}$.

Com efeito, essa é a base para o desenvolvimento da amizade entre os povos, a formação de uma comunidade mundial capaz de viver a fraternidade de modo concreto ${ }^{38}$. Por isso, urge o exercício do diálogo, condição para verdadeira aproximação, entendimento mútuo e convivência pacífica, tornando o mundo melhor para toda a humanidade ${ }^{39}$. Desse modo, cuida-se do mundo, tecendo a paz por meio de pontos que geram

\footnotetext{
30 LS Cap. IV.

31 LS Cap. V.

32 LS Cap. VI.

33 FT 6.

34 FT, Cap. I.

35 FT 56.

36 FT 87.

37 FT 128.

38 FT 154.

39 FT 198.
} 
processos de relações renovadas no horizonte da fraternidade ${ }^{40}$. Por fim, recorda-se o importante papel que as várias religiões têm nesse trabalho, sendo elas as primeiras promotoras da justiça, da fraternidade e da paz ${ }^{41}$.

\section{O princípio do bem comum, a paz social e a justiça intergeracional}

O princípio do bem comum é referenciado na Evangelii Gaudium associado à paz social, entendida não como uma mera ausência de violência conquistada por meio da imposição de uma das partes, muito menos resultado de um consenso de escritório ou a paz de uma efêmera minoria. Mas, assumindo o ensino do Papa Paulo VI, Francisco aponta para uma paz que é construída no dia a dia, que busca a ordem querida por Deus e que traz em si a justiça entre os seres humanos ${ }^{42}$.

Na Evangelii Gaudium, Francisco recorda que para a construção da paz, da justiça e da fraternidade são necessários quatro princípios:

$a$ - O tempo é superior ao espaço: "o tempo ordena os espaços, ilumina-os e transforma-os em elos duma cadeia em constante crescimento" ${ }^{43}$. Em sentido amplo, tempo aqui é entendido como "tempo de processos"; 44

$b$ - A unidade prevalece sobre o conflito: o conflito não deve ser ignorado ou potencializado, mas deve ser resolvido e transformado em elo de um novo processo. A paz exige solidariedade, na qual é possível desenvolver-se comunhão em meio às diferenças, relacionadas e harmonizadas pela ação do Espírito Santo, ${ }^{45}$

$c-A$ realidade é mais importante que a ideia: essa é a dimensão real da vida. As elaborações conceituais precisam estar a serviço da realidade, de modo que ideia e realidade estejam juntas, ${ }^{46}$

\footnotetext{
$40 \quad$ FT 225.

41 FT 271.

42 EG 218.

43 EG 223.

44 WOLFF, 2018, p. 47

45 EG 226-230.

46 EG 231-233.
} 
$d$-O todo é superior à parte: tal perspectiva exige uma unidade entre o global e o local. É preciso estar atento à realidade global, para não viver de modo mesquinho, mas também é preciso saber que é no local em que se caminha com os pés no chão. O todo é mais que a soma das partes e, portanto, em qualquer lugar e ambiente é preciso alargar o olhar para perceber o bem maior que trará benefícios a todas as pessoas. ${ }^{47}$

Nesse sentido, vê-se que o primado do bem comum percorre as encíclicas do Papa Francisco, e na Laudato Si afirma que "tudo está interligado". ${ }^{48}$ Deste modo, para uma ecologia humana, o princípio do bem comum tem um papel central e unificador na ética social ${ }^{49}$. Esse princípio implica no respeito e na promoção dos direitos fundamentais inalienáveis de toda pessoa, garantias do seu desenvolvimento integral. ${ }^{50}$

No atual cenário sociocultural, em que cada vez mais aumenta o número de pessoas descartadas, privadas dos direitos humanos básicos, o princípio do bem comum apresenta-se como "um apelo à solidariedade e uma opção preferencial pelos mais pobres. Esta opção implica tirar as consequências do destino comum dos bens da terra". ${ }^{51}$ A política é um dos meios pelos quais se constroem os projetos a longo prazo para o desenvolvimento de todos e do bem comum. Isso urge a soma dos esforços, superando toda polarização. ${ }^{52}$ Constrói-se, assim, sociedades abertas, que integrem a todos e a todas, sem tratar alguém como estranho apenas por sua cor, etnia, ideologia ou credo. Num mundo de relações fraternas, não há corpos estranhos, todos convivem na fraternidade e partilham do bem comum. ${ }^{53}$

O maior desafio aqui é a superação dos individualismos. A cultura pós-moderna incentiva posturas subjetivistas que tendem ao isolamento entre pessoas e povos. Muitos dos atuais problemas sociais se enraízam numa busca egoísta de satisfação imediata dos próprios interesses, isolando-se no indiferentismo em relação ao outro. E mesmo a soma dos interesses individuais é incapaz de construir um mundo melhor

\footnotetext{
47 EG 234-235.

48 LS 91.

49 LS 156.

50 LS 157.

51 LS 158.

52 FT 15.

53 FT 97.
} 
para toda a humanidade ${ }^{54}$. A vida social precisa estar estruturada numa política justa para garantir comunidade, com relações justas e pacíficas entre pessoas, povos e nações, numa verdadeira "amizade social" $"$. Tal política exige líderes populares capazes de unir as pessoas com base a projetos transformação e crescimento humano global ${ }^{56}$. Tem-se, assim, caminho seguro para as gerações futuras ${ }^{57}$. Urge refletir sobre o que elas irão herdar da geração atual. Urge planejar para as gerações futuras um planeta habitável ${ }^{58}$ e não apenas ruínas, desertos e lixo ${ }^{59}$. Para isso, faz-se necessário ampliação de horizontes de interesses, pessoal e coletivamente, para perceber quem hoje está à margem do desenvolvimento e quem poderá estar também no futuro. ${ }^{60}$

Portanto, o percurso para a paz é uma responsabilidade coletiva, por meio da qual cada pessoa pode, por meios distintos, trabalhar em prol do bem comum ${ }^{61}$. Particular responsabilidade nisso tem as pessoas religiosas. A partir de sua fé, precisam encontrar espaços de diálogo e cooperação na construção do bem comum, de modo que cada tradição religiosa poderá enriquecer a vivência humana com suas contribuições sobre o sentido da vida que colhem do Mistério ${ }^{62}$.

\section{A opção preferencial pelos pobres}

O pontificado de Francisco apresenta-se como importante força para a opção que a igreja católica na América Latina, na Conferência de Puebla (1979) fez pela opção preferencial pelos pobres. Nesse sentido, Francisco ao propor uma igreja na perspectiva do Vaticano II, faz também sintonia com a eclesiologia latino-americana, que denuncia profeticamente o que contradiz o projeto evangélico de vida na paz e na justiça ${ }^{63}$. Isso faz com que o kerigma tenha repercussões sociais

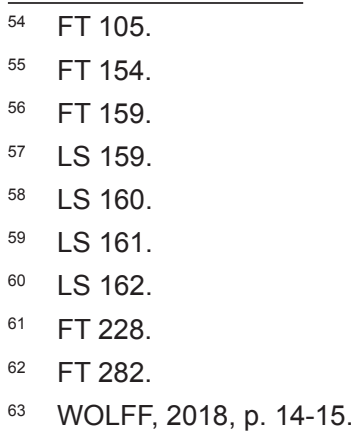


concretas nas comunidades religiosas e na sociedade como um todo ${ }^{64}$. A eclesiologia conciliar e latino-americana orientam o olhar de fiéis em Cristo para reconhecê-lo nas pessoas que vivem em situações de pobreza extrema ${ }^{65}$. Para o pontífice, a preocupação pelo desenvolvimento integral dos pobres e dos marginalizados deriva da fé em Cristo ${ }^{66}$. Isso não é mera opção teórica, mas um estilo de vida. O Papa Francisco "optou por um estilo de vida pobre, simples, abnegado como coerência da continuidade da opção pelos pobres" ${ }^{\circ 7}$.

Os pobres são os que mais sofrem com a deterioração do planeta. Eles são vítimas das doenças causadas pela poluição ${ }^{68}$, afetados diretamente pelas mudanças climáticas ${ }^{69}$, o aquecimento global ${ }^{70}$, privados de água limpa e potável ${ }^{71}$, carentes de saneamento básico ${ }^{72}$. São, consequências do fato de serem vítimas do sistema econômico, que os têm à margem do mercado e por isso também não lhes permite sequer acesso aos recursos básicos ${ }^{73}$. Pela dificuldade na habitação, os pobres são jogados nas periferias das grandes cidades, numa vida marcada pela violência ${ }^{74}$. Assim, fica claro que boa parte da humanidade é sacrificada em benefício de alguns setores da sociedade. ${ }^{75}$

A vida social em situação indigna para o ser humano é vinculada com a degradação ambiental. Para Francisco, não se resolve os problemas sociais de forma isolada dos problemas ambientais, de modo que humanidade integral se vincula com uma "ecologia integral", que exige ouvir "tanto o clamor da terra como o clamor dos pobres"76. Nesse sentido, o direito dos povos, a dignidade dos pobres e o respeito ao meio

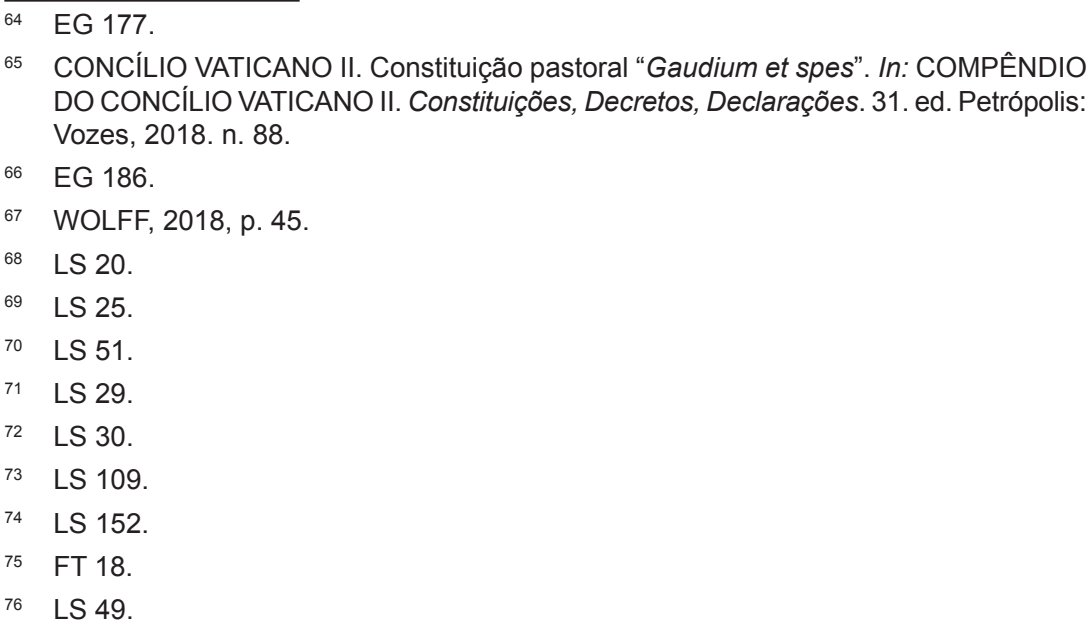


ambiente devem estar acima da liberdade de empresa ou de mercado ${ }^{77}$. A prioridade deve ser a erradicação da miséria e o desenvolvimento humano integral ${ }^{78}$. Isso é o que garante o sentido da vida no presente e dá confiança no futuro. Assim, a prática da caridade assistencial deve ser sempre algo provisório, enfrentando situações emergenciais. A caridade verdadeira dá à pessoa condições para garantir a própria existência, pelo trabalho digno ${ }^{79}$, o que exige uma política que assegure direitos humanos e ambientais para todas as pessoas e todos os povos. ${ }^{80}$

Entre os meios necessários para garantir a justiça socioambiental, destaca-se o urgente desenvolvimento de políticas públicas e legislações internacionais, nacionais e locais, sob o princípio do bem comum, a médio e longo prazo, superando o consumismo, desenvolvendo cooperativas, a agricultura e a infraestrutura, reduzindo o consumo energético e a poluição, fazendo boa gestão dos transportes e protegendo a vida ${ }^{81}$. Faz diferença nisso o enfrentamento da degradação do meio ambiente, com reações globais efetivas para a redução da poluição e o desenvolvimento dos países e regiões pobres. ${ }^{82}$

É preciso reconhecer a dignidade do pobre, respeitando-o no seu estilo próprio e na cultura e integrá-los de fato na sociedade, por meio de estratégias de expressão e participação social. Basta de contensão e de obras altruístas que os reduzem à passividade ${ }^{83}$. Para tanto, é necessária uma boa política, que priorize o amor que se expressa próximo e concreto $^{84}$, fundamentada em princípios e no bem comum ${ }^{85}$.

A promoção da amizade social implica em aproximar os grupos sociais distantes, bem como renovar o encontro com os mais pobres e vulneráveis, de modo a reconhecer e afirmar a dignidade de cada pessoa, a fim de que elas assumam o protagonismo da sua nação ${ }^{86}$. Convém ressaltar que se, por vezes, os pobres e os descartados da sociedade reagem

\footnotetext{
FT 122.

LS 172

79 LS 128.

80 FT 169.

81

82

83 
com atitudes que parecem antissociais, é porque, por muitas vezes, foram marcados pelo desprezo e pela falta de inclusão social ${ }^{87}$. Diante disso, recordam os bispos da América Latina "só a proximidade que nos faz amigos nos permite apreciar profundamente os valores dos pobres de hoje, seus legítimos desejos e seu modo próprio de viver a fé. A opção pelos pobres deve conduzir-nos à amizade com os pobres". ${ }^{88}$

Francisco afirma que cada pessoa é chamada a cuidar do mundo e da qualidade de vida da humanidade e do planeta, com relações solidárias ${ }^{89}$. A maior parte da humanidade se declara crente, e isso é algo positivo para incentivar as religiões a assumirem o diálogo como caminho para a realização de projetos comuns a favor das populações carentes em todo o mundo ${ }^{90}$. Para os cristãos, convém acentuar que Jesus, retomando a fé bíblica no Deus criador, destaca que Deus é Pai ${ }^{11}$ e estabelece com todas as criaturas relações de ternura e de fraternidade. Jesus afirma, ainda, que benditas são as pessoas que dão de comer aos que têm fome, de beber a quem tem sede, acolhem os forasteiros, vestem os nus, visitam os doentes e os presos. ${ }^{92}$

\section{Por uma ecologia integral}

A Laudato Si é reconhecida como a carta magna do magistério pontifico no que diz respeito a questão ecológica, de modo que essa encíclica coroa os documentos anteriores, com a sua proposta: a ecologia integral ${ }^{93}$. Por meio dessa encíclica, o papa apresenta uma ecologia integral, que articula as dimensões ambiental, econômica, política, social, cultural e da vida cotidiana, relacionando-as com o princípio do bem comum ${ }^{94}$. Uma ecologia integral precisa ser vivida com alegria e

\footnotetext{
87 FT 234.

88 CONSELHO EPISCOPAL LATINO-AMERICANO. Documento de Aparecida. Texto conclusivo da V Conferência Geral do episcopal Latino-Americano e do Caribe. Brasília: Edições CNBB; São Paulo: Paulus: Paulinas, 2007. n. 389.

89 LS 232.

90 LS 201.

91 Mt 11,25.

92 Mt 11,34-36.

93 MAÇANEIRO, 2016, p. 268.

94 MURAD, Afonso. Laudato Si e a Ecologia Integral. Um novo capítulo da Doutrina Social da Igreja. Medellín, Bogotá. v. 43, n. 168, p. 469-494. maio/ago. 2017. p. 469.
} 
autenticidade $^{95}$, aberta a várias categorias que se colocam em contato com a essência do ser humano. ${ }^{96}$

Compreendendo que na realidade tudo está intimamente relacionado, bem como os problemas atuais que exigem um olhar e compromissos globais, a encíclica Laudato $\mathrm{Si}^{\prime}$ indica diferentes elementos, considerando as dimensões ambientais, humanas e sociais ${ }^{97}$, observando as relações entre os organismos vivos e o meio ambiente onde se desenvolvem ${ }^{98}$. Assim, Francisco apresenta as várias faces de uma ecologia integral:

$a$-Ecologia ambiental: ao se referir ao "meio ambiente", o pontífice acentua a particular relação entre a natureza e a sociedade. Desse modo, há uma única e complexa crise socioambiental, que só poderá ser superada a partir de uma abordagem integral, que vise combater a pobreza, devolver a dignidade aos excluídos e, concomitante, cuidar da natureza. ${ }^{99}$

$b$-Ecologia Econômica: o crescimento econômico possui a tendência de produzir automatismos e a homogeneizar, visando simplificar os processos e reduzir os custos. Assim, é necessária uma ecologia econômica, que seja capaz de considerar a realidade, na sua ampla dimensão, e que esteja a serviço da proteção do meio ambiente. Na perspectiva integral e integradora, é inseparável a análise dos contextos humanos, familiares, laborais, urbanos e da relação de cada pessoa consigo mesma, que produz uma maneira específica de se relacionar com os outros e com o meio ambiente. ${ }^{100}$

c-Ecologia Social: se tudo se inter-relaciona, então, a saúde das instituições sociais atinge o ambiente e a qualidade de vida humana. Diante disso, é necessária uma ecologia social, que seja institucional e, de maneira progressiva, atinja as diferentes dimensões, percorrendo desde a família, como grupo social primário, até a vida internacional, perpassando a comunidade local e a nação. ${ }^{101}$

\begin{tabular}{ll}
\hline 95 & LS 10. \\
96 & LS 11. \\
97 & LS 137. \\
98 & LS 138. \\
99 & LS 137-139. \\
100 & LS 141. \\
101 & LS 142.
\end{tabular}


$d$-Ecologia cultural: junto ao patrimônio natural, encontra-se ameaçado o patrimônio histórico, artístico e cultural, que constituem a identidade comum de um espaço. É necessário integrar a história, a cultura e a arquitetura de um determinado lugar, guardando a sua identidade original. Portanto, a ecologia contempla também o cuidado com as riquezas culturais da humanidade ${ }^{102}$. Diferentes formas de exploração intensa e de degradação podem consumir também os recursos sociais, a identidade cultural e o sentido da convivência social e da existência, que constituíram um modo de vida, durante um longo tempo. Assim, o desaparecer de uma cultura é também uma situação grave. ${ }^{103}$

$e-$ Ecologia da vida cotidiana: o ambiente em que cada ser humano vive tem influência na sua maneira de viver, sentir e agir, a começar pelo quarto, a casa, o local em que se trabalha e o bairro, que expressam a identidade de cada sujeito ${ }^{104}$. Em virtude da relação que existe entre os espaços urbanizados e o comportamento humano, é preciso que, ao se projetar e construir edifícios, bairros, espaços públicos e cidades, sejam valorizados os vários saberes ${ }^{105}$. É necessário reconhecer também que é o corpo que permite ao ser humano relacionar-se, assim, a "aceitação do próprio corpo como dom de Deus é necessária para acolher e aceitar o mundo inteiro como dom do Pai e casa comum"106 , condição de uma verdadeira ecologia humana ${ }^{107}$.

\section{A fraternidade e a amizade social: um sonho possível}

Francisco de Roma faz referência a Francisco de Assis ao acolher os seus conselhos e destacar o convite a um amor que ultrapasse as barreiras geográficas para que, de modo fraterno, reconheça, valorize e ame as pessoas, independentemente de sua proximidade física e do local do planeta em que nasceu ou habita ${ }^{108}$. Ainda sobre Francisco de Assis, o papa indica que ele não fazia dialética, impondo doutrinas, mas

\footnotetext{
102 LS 143.

103 LS 145-146.

104 LS 147.

105 LS 150.

106 LS 155.

107 LS 155.

108 FT 1.
} 
comunicava o amor Deus, pois compreendia que "Deus é amor: quem permanece no amor, permanece em Deus" ${ }^{109}$. Assim, Deus, o Pai, suscita uma sociedade fraterna. ${ }^{110}$

Deus criou os seres humanos iguais nos direitos, nos deveres e na dignidade e os chamou à convivência fraterna ${ }^{111}$. Nessa convivência, cada pessoa fortalece o anseio mundial para que a vida seja "uma bela aventura". A vida não acontece isoladamente, mas em comunidade, na qual as pessoas se ajudam e se apoiam mutuamente. "Como é importante sonhar juntos [...]. Sonhemos como uma única humanidade, como caminhantes da mesma carne humana, como filhos desta mesma terra que nos alberga a todos, cada qual com a riqueza da sua fé ou das suas convicções, cada qual com a própria voz, mas todos irmãos". ${ }^{112}$

Há muitas situações no mundo atual que dificultam a fraternidade universal ${ }^{113}$ : conflitos anacrônicos; nacionalismos fechados e agressi$\operatorname{vos}^{114}$; uma economia global, com o seu modelo cultural único ${ }^{115}$; as diversas expressões de racismo ${ }^{116}$; as regras econômicas que focam apenas a riqueza e não a equidade ${ }^{117}$; os direitos humanos que não são iguais para todos ${ }^{118}$; o trabalho escravo ${ }^{119}$; a questão das migrações, que ainda causam alarmes e temores, fomentada pela mensalidade xenófoba ${ }^{120}$; os movimentos digitais que têm sido marcados pelo ódio e destruição ${ }^{121}$; a perda da capacidade de escuta e de diálogo ${ }^{122}$.

É preciso enfrentar essas situações com a parresia da fé. Em meio às sombras, é preciso lançar a luz do Evangelho, apontando para Cristo

\footnotetext{
109 1Jo 4,16.

110 FT 4.

111 FT 5.

112 FT 8.

113 FT 9.

114 FT 11.

115 FT 12.

116 FT 20.

117 FT 21.

118 FT 22.

119 FT 24.

120 FT 37-41.

121 FT 42-46.

122 FT 47-50.
} 
como a "luz que ilumina toda pessoa" 123 . Então, frente às dificuldades, caminha-se na esperança ${ }^{124}$, pois "a esperança é ousada, sabe olhar para além das comodidades pessoais, das pequenas seguranças e compensações que reduzem o horizonte, para se abrir aos grandes ideais que tornam a vida mais bela e digna. Caminhemos na esperança!" 125 . Para tanto, é necessário que a sociedade se oriente para o bem comum e, a partir desse objetivo, "reconstrua incessantemente a sua ordem política e social, o tecido das suas relações, o seu projeto humano" 126 . Os seres humanos podem refazer a comunidade humana, assumindo a própria fragilidade e a dos outros, não permitindo que se construa uma sociedade de exclusão, mas fazendo-se próximos e solidários para com quem está caído, e possibilitando-lhe partilhar ${ }^{127}$. Não se pode viver sendo indiferente à dor; não se pode deixar ninguém caído "nas margens da vida". Essa consciência deve transformar o jeito de ser de cada pessoa. ${ }^{128}$

O ser humano compreende a si mesmo, mediante uma teia de relações, de modo que uma relação sadia consigo mesmo permita abrir-se aos outros, podendo crescer e enriquecer-se mutuamente ${ }^{129}$. A comunhão universal é vivida no amor, que, em sua própria dinâmica, exige uma abertura, capacidade de acolhida dos outros, numa aventura sem fim, que faz com que se dirija para o sentido de uma mútua pertença ${ }^{130}$. Disse Jesus: "Todos vós sois irmãos"131. Desse modo, o amor rompe com as fronteiras entre os povos, possibilitando a abertura universal ${ }^{132}$ que gera uma "amizade social" genuína. O futuro não é monocromático, mas diverso devido à contribuição que cada um e cada uma pode dar. De fato, a família humana precisa "aprender a viver conjuntamente em harmonia e paz, sem necessidade de sermos todos iguais!"133.

\footnotetext{
123 Jo 1,9 .

124 FT 54.

125 FT 55.

126 FT 66.

127 FT 67.

128 FT 68.

129 FT 89.

130 FT 67.

131 Mt 23,8.

132 FT 99.

133 FT 100.
} 
Por isso o direito que todo ser humano tem para desenvolver-se integralmente ${ }^{134}$. E o que é individual não pode ser individualista, o pessoal é também coletivo: "voltemos a promover o bem, para nós mesmos e para toda a humanidade, e assim caminharemos juntos para um crescimento genuíno e integral" 135 , manifestando a solidariedade de modo concreto no serviço, cuidando dos mais frágeis presentes na família, na sociedade e no povo ${ }^{136}$. A construção da fraternidade universal exige uma política a serviço do bom comum ${ }^{137}$, garantindo direitos como: trabalho digno para todos e todas ${ }^{138}$; educação para que o ser humano seja artífice do seu trabalho ${ }^{139}$; hábitos solidários, com capacidade de refletir a vida de maneira integral. Assim, a sociedade como um todo reage "face às próprias injustiças, às aberrações, aos abusos dos poderes econômicos, tecnológicos, políticos e midiáticos" ${ }^{140}$.

Vale ressaltar que a civilização do amor é construída como amor social ${ }^{141}$, que é a força capaz de "suscitar novas vias para enfrentar os problemas do mundo de hoje e para e renovar profundamente desde o interior das estruturas, organizações sociais, ordenamentos jurídicos" ${ }^{142}$. A construção da paz exige esforços diários e o compromisso de todos ${ }^{143}$. A caridade apresenta-se, nesse sentido, o centro da vida social ${ }^{144}$, que, aberta à verdade ${ }^{145}$, é capaz de acompanhar quem sofre e modificar as condições sociais que geram sofrimento ${ }^{146}$. Caridade é encontro, que possibilita compromissos comuns e diálogo na verdade ${ }^{147}$. Cada pessoa pode expressar-se em sua identidade e sentir-se acolhida, reconhecida, promovida. Por isso, o magistério de Francisco tem o encontro e o diálogo como "cultura" a ser criada com urgência no mundo atual, construindo

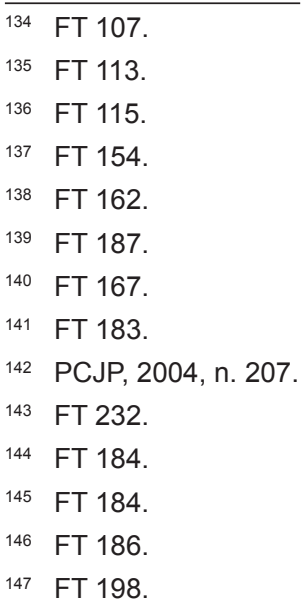


pontes para unir o que está dividido. E "isto se tornou uma aspiração e um estilo de vida. O sujeito desta cultura é o povo, não um setor da sociedade que tenta manter tranquilo o resto com recursos profissionais e mediáticos ${ }^{148}$.

Por fim, como caminho para curar as feridas, é preciso sermos artesãos da paz, que iniciem processos de cura ${ }^{149}$. É preciso trabalharmos juntos ${ }^{150}$, no serviço aos demais, e não na ambição de dominá-los ${ }^{151}$. Esse caminho requer reconciliação e perdão. Não se trata de renunciar os próprios direitos, mas de amar o opressor, que não significa consentir que ele continue agindo, nem o levar a pensar que aceitável o que faz. O importante é não alimentar o ódio que faz mal à pessoa e ao povo, desencadeando a vingança. Pois, desse modo nada se ganha nas relações, e perde-se tudo o que foi construído no caminho da fraternidade. ${ }^{152}$

\section{Considerações finais}

A DSI tem sido desvelada a cada dia, acentuada pela atuação social que o papa tem realizado. Francisco, conduzindo a Igreja na sua missão de anunciar o Evangelho do Reino, tem no seu coração a plenitude do Reino. Movido pela fé no Ressuscitado, o papa jamais esquece que o caminho para ele e dá-se no chão da história, de modo que, atento às múltiplas questões do tempo presente, inicia processos que objetivam responder os seus desafios.

O pontificado de Francisco é marcado pelo diálogo, como estilo de vida e proposta eclesial. Caracteriza-se pela proximidade, escuta, esforço para entender o outro, construir pontes. Isso incide positivamente tanto no interior da igreja quanto no mundo. Caracteriza a "igreja em saída missionária", companheira e serva, disposta a ajudar o mundo nas suas necessidades, a curar suas feridas, planejar e iniciar processos de transformação.

\footnotetext{
148 FT 217.

149 FT 225.

150 FT 228.

151 FT 229.

152 FT 236-242.
} 
O fundamento é a fé no Deus que assim agiu com quem sofria na escravidão do Egito ${ }^{153}$. Esse Deus se humanizou e se solidarizou para com a humanidade ${ }^{154}$. Desse modo, a fé cristã impele à caridade social. A doutrina social da Igreja é uma privilegiada expressão do Evangelho do amor que visa transformar o mundo na perspectiva do Reino. Ali se realiza o desejo de Cristo: que todos tenham vida em abundância ${ }^{155}$. Aqui a razão dos esforços de Francisco para o desenvolvimento de um humanismo integral, uma ecologia integral, a fraternidade e amizade social.

\section{Referências}

BÍBLIA. Português. Bíblia de Jerusalém. Nova edição renovada e ampliada. São Paulo: Paulus, 2015.

CIPRIANI, Gabriele. Da fraternidade à comunhão: o ecumenismo do papa Francisco. Caminhos de Diálogo, Curitiba, ano 6, n. 8, p. 8-18, jan.jun. 2018.

CONCÍLIO VATICANO II. Constituição pastoral "Gaudium et spes". In: COMPÊNDIO DO CONCÍLIO VATICANO II. Constituições, Decretos, Declarações. 31. ed. Petrópolis: Vozes, 2018. p. 143-256.

CONSELHO EPISCOPAL LATINO-AMERICANO. Documento de Aparecida. Texto conclusivo da V Conferência Geral do episcopal Latino-Americano e do Caribe. Brasília: Edições CNBB; São Paulo: Paulus: Paulinas, 2007.

FRANCISCO, Papa. Carta Encíclica Fratelli Tutti. São Paulo: Paulinas, 2020. p. 209.

FRANCISCO, Papa. Carta Encíclica Laudato Si. São Paulo: Paulus: Loyola, 2015. p. 142.

FRANCISCO, Papa. Exortação Apostólica Evangelli Gaudium. São Paulo: Paulus: Loyola, 2014. p. 165.

LEÃO XIII, Papa. Carta Encíclica Rerum Novarum: sobre a condição dos operários. Disponível em: http://www.vatican.va/content/leo-xiii/pt/

\footnotetext{
153 Ex 3.

154 Jo 1,14 .

155 Jo 10,10 .
} 
encyclicals/documents/hf_l-xiii_enc_15051891_rerum-novarum.html. Acesso em: 15 fev. 2021.

MAÇANEIRO, Marcial. A ecologia e o ensino social da Igreja: inscrição e alcances de um paradigma. In: ZACHARIAS, Ronaldo; MANZINI, Rosane (org.). Magistério e doutrina social da Igreja. São Paulo: Paulinas, 2016. p. 230-283.

MAÇANEIRO, Marcial. Ecologia, fé e justiça social: Para uma recepção da encíclica 'Laudato si'de Papa Francisco. Medellín, Bogotá. v. 41. n. 163, p. 435-460. set./dez. 2015.

MAÇANEIRO, Marcial. Vozes do sul na encíclica Laudato si': Fontes e temas. Pistis \& Praxis - Teologia e Pastoral. Curitiba, v. 8 . n. 3, p. 715-760. set./dez. 2016.

MARTINS, Alexandre Andrade. Doutrina Social da Igreja e Teologia da Libertação: diferentes abordagens. In: ZACHARIAS, Ronaldo; MANZINI, Rosane (org.). Magistério e doutrina social da Igreja. São Paulo: Paulinas, 2016. p. 50-82.

MURAD, Afonso. Laudato Si e a Ecologia Integral. Um novo capítulo da Doutrina Social da Igreja. Medellín, Bogotá. v. 43. n. 168, p. 469-494. maio/ago. 2017.

PONTIFÍCIO CONSELHO JUSTIÇA E PAZ. Compêndio da Doutrina Social da Igreja. Disponível em: http://www.vatican.va/roman_curia/pontifical_councils/justpeace/documents/rc_pc_justpeace_doc_20060526 compendio-dott-soc_po.html. Acesso em: 8 jan. 2021.

STRINGHINI, Pedro Luiz. Apresentação. In: ZACHARIAS, Ronaldo; MANZINI, Rosane (org.). Magistério e doutrina social da Igreja. São Paulo: Paulinas, 2016. p. 5-7.

WOLFF, Elias. Igreja em diálogo. São Paulo: Paulinas, 2018. 